\title{
Use of PET/CT to aid clinical decision-making in cases of solitary pulmonary nodule: a probabilistic approach
}

Uso da PET/CT no auxílio à decisão de tomada clínica no nódulo pulmonar solitário: uma abordagem probabilística

\section{Felipe Alves Mourato ${ }^{1, a}$, Ana Emília Teixeira Brito ${ }^{1, b}$, Monique Sampaio Cruz Romão ${ }^{1, c}$, Renata Guerra Galvão Santos $^{1, \mathrm{~d}}$, Cristiana Altino de Almeida ${ }^{1, \mathrm{e}}$, Paulo José de Almeida Filho ${ }^{1, f}$, Aline Lopes Garcia Leal ${ }^{1, \mathrm{~g}}$}

1. Real Hospital Português de Beneficência em Pernambuco, Recife, PE, Brazil.

Correspondence: Dr. Felipe Alves Mourato. Real Hospital Português de Beneficência em Pernambuco - Real Nuclear. Avenida Portugal, 163, Paissandu. Recife, PE, Brazil, 52010-010. Email: felipe.a.mourato@gmail.com.

a. https://orcid.org/0000-0001-8102-9654; b. https://orcid.org/0000-0002-1065-9672; c. https://orcid.org/0000-0003-0043-213X; d. https://orcid.org/0000-0002-5201-5066; e. https://orcid.org/0000-0002-9400-7099; f. https://orcid.org/0000-0002-3584-5316; g. https://orcid.org/0000-0002-3050-1119.

Received 28 February 2019. Accepted after revision 12 July 2019.

How to cite this article:

Mourato FA, Brito AET, Romão MSC, Santos RGG, Almeida CA, Almeida Filho PJ, Leal ALG. Use of PET/CT to aid clinical decision-making in cases of solitary pulmonary nodule: a probabilistic approach. Radiol Bras. 2020 Jan/Fev;53(1):1-6.

Abstract Objective: To determine the frequency with which ${ }^{18} \mathrm{~F}$-FDG-PET/CT findings change the probability of malignancy classification of solitary pulmonary nodules.

Materials and Methods: This was a retrospective analysis of all ${ }^{18} \mathrm{~F}-\mathrm{FDG}-\mathrm{PET} / \mathrm{CT}$ examinations performed for the investigation of a solitary pulmonary nodule between May 2016 and May 2017. We reviewed medical records and PET/CT images to collect the data necessary to calculate the pre-test probability of malignancy using the Swensen model and the Herder model. The probability of malignancy was classified as low if $<5 \%$, intermediate if $5-65 \%$, and high if $>65 \%$. Cases classified as intermediate in the Swensen model were reclassified by the Herder model.

Results: We reviewed the records for 33 patients, of whom 17 (51.5\%) were male. The mean age was $68.63 \pm 12.20$ years. According to the Swensen model, the probability of malignancy was intermediate in 23 cases (69.7\%). Among those, the application of the Herder model resulted in the probability of malignancy being reclassified as low in 6 (26.1\%) and as high in 8 (34.8\%).

Conclusion: ${ }^{18} \mathrm{~F}-\mathrm{FDG}$-PET/CT was able to modify the probability of malignancy classification of a solitary pulmonary nodule in more than $50 \%$ of the cases evaluated.

Keywords: Solitary pulmonary nodule; Positron emission tomography; Decision support techniques; Clinical decision-making; Medical oncology; Pulmonary medicine.

Resu mo Objetivo: Determinar a frequência em que a PET/CT com FDG ${ }^{18} \mathrm{~F}$ muda a classificação de probabilidade de malignidade do nódulo pulmonar solitário.

Materiais e Métodos: Foi realizada análise retrospectiva de todas as PET/CTs com $\mathrm{FDG}-{ }^{18} \mathrm{~F}$ realizadas entre maio/2016 e maio/2017 num serviço de medicina nuclear, cuja indicação era a avaliação de nódulo pulmonar solitário. Foram analisados os prontuários e os exames de PET/CT para coleta das informações necessárias para o cálculo da probabilidade pré-teste de malignidade pelo modelo de Swensen e modelo de Herder. Probabilidade menor que $5 \%$ foi considerada como baixa, maior que $65 \%$ foi definida como alta, e os casos restantes, como intermediária. Os casos classificados como intermediários pelo modelo de Swensen foram reclassificados de acordo com o modelo de Herder.

Resultados: Trinta e três pacientes foram incluídos neste estudo, 17 (51,5\%) deles eram do gênero masculino, e a média de idade foi 68,63 anos ( $\pm 12,20$ anos). Em relação à classificação da probabilidade de malignidade pelo modelo de Swensen, 23 (69,7\%) apresentaram probabilidade intermediária de malignidade. Destes, o modelo de Herder classificou 6 casos (26,1\%) como probabilidade baixa e 8 casos $(34,8 \%)$ como probabilidade alta de malignidade.

Conclusão: A PET/CT com FDG- ${ }^{18} \mathrm{~F}$ foi capaz de modificar a classificação probabilística do nódulo pulmonar solitário em mais da metade dos casos.

Unitermos: Nódulo pulmonar solitário; Tomografia por emissão de pósitrons; Técnicas de suporte a decisão; Tomada de decisão clínica; Oncologia; Pneumologia.

\section{INTRODUCTION}

A solitary pulmonary nodule (SPN) is a round or oval pulmonary opacity of up to $3 \mathrm{~cm}$ in diameter, surrounded by normal lung parenchyma, that is not accompanied by pleural effusion, pneumonia, or adenopathy ${ }^{(1)}$. A SPN is found in $0.09-2 \%$ of all chest $X$-rays ${ }^{(2)}$ and in up to $51 \%$ of chest tomography scans in populations at high risk for lung cancer $^{(3)}$. The etiological investigation of a SPN depends 
on its pre-test probability of malignancy ${ }^{(1,4,5)}$. Cases with low probability of malignancy $(<5 \%)$ are usually managed by active surveillance, whereas those with high probability $(>65 \%)$ biopsy or surgery is indicated ${ }^{(1,5)}$. Cases with intermediate probability of malignancy are usually biopsied for diagnostic clarification ${ }^{(6)}$. However, biopsy is an invasive procedure that can lead to a significant number of false-negative results ${ }^{(7)}$. The use of PET/CT with ${ }^{18} \mathrm{~F}$ FDG $\left({ }^{18} \mathrm{~F}\right.$-FDG-PET/CT $)$ can help to define the management of intermediate cases by reclassifying them as having low, intermediate, or high probability of malignancy ${ }^{(1)}$, thus reducing the number of invasive procedures and the total cost of treatment ${ }^{(8)}$. However, there are no studies evaluating the frequency with which ${ }^{18}$ F-FDG-PET/CT determines a change in the probability of malignancy classification of SPNs, from intermediate to low or high.

Because ${ }^{18}$ F-FDG is a glucose analogue and tumor cells usually have an increased glycolytic metabolismdue to an increased glycolytic enzyme activity and to the overexpression of glucose transporters ${ }^{(9)}$ - the tumor cells have enhanced ${ }^{18} \mathrm{~F}$-FDG uptake, which makes them visible on ${ }^{18}$ F-FDG-PET/CT images. Therefore, it is possible to distinguish benign from malignant lesions in various conditions, including SPNs. Although the uptake in malignant lesions is usually more intense, the distinction is not always clear, because some benign conditions can also present increased ${ }^{18} \mathrm{~F}$-FDG uptake, leading to falsepositive results, whereas some malignant lesions may not have affinity for ${ }^{18} \mathrm{~F}-\mathrm{FDG}{ }^{(10)}$.

The SPN pre-test probability of malignancy is defined on the basis of clinical and radiological data. The first model, proposed by Swensen et al. ${ }^{(11)}$, is known as the Mayo Clinic model. That model includes the following clinical variables: age; previous or current smoking; history of extrathoracic cancer; nodule size; presence of nodule spiculation; and nodule location. In 2005, Herder et al. ${ }^{(12)}$ described a new method for calculating the pretest probability of malignancy. Their model includes all variables of the Mayo Clinic model plus an assessment of ${ }^{18} \mathrm{~F}$-FDG uptake by the SPN, as seen on ${ }^{18} \mathrm{~F}$-FDG-PET/ CT. This new approach resulted in higher accuracy lev$\mathrm{els}^{(13)}$. However, ${ }^{18} \mathrm{~F}$-FDG-PET/CT is performed in cases classified by the Mayo Clinic model as intermediate probability only ${ }^{(1)}$. Therefore, ${ }^{18}$ F-FDG-PET/CT is expected to reclassify intermediate probability cases as low $(<5 \%)$ or high $(>65 \%)$ probability, probabilistically defining the best management for each case.

The purpose of this study was to determine how often ${ }^{18}$ F-FDG-PET/CT changes the SPN pre-test malignancy classification, based on the probability models described, during the clinical decision-making process.

\section{MATERIALS AND METHODS}

This was a retrospective study based on the analysis of all ${ }^{18}$ F-FDG-PET/CT scans performed between May 1,
2016 and May 31, 2017 at a nuclear medicine center. All ${ }^{18} \mathrm{~F}$-FDG-PET/CT scans that were requested for SPN investigation were included. The retrospective analysis of the data was approved by the local research ethics committee (Reference no. 76305317.4.0000.5199).

All ${ }^{18} \mathrm{~F}$-FDG-PET/CT scans were performed with the same device (Biograph 16; Siemens Healthcare, PA, USA) approximately $60 \mathrm{~min}$ after intravenous administration of $3.7-4.8 \mathrm{MBq} / \mathrm{kg}$ of ${ }^{18} \mathrm{~F}$-FDG. The PET images were obtained from the base of the skull to the proximal third of the lower limbs in three-dimensional mode, each body segment position being scanned for $3 \mathrm{~min}$. The images obtained were processed by iterative reconstruction (two iterations of eight subsets with a Gaussian filter). Computed tomography (CT) image acquisition parameters included a slice thickness of $5 \mathrm{~mm}$, a voltage of $120 \mathrm{kV}$, and no intravenous contrast administration. In addition, a high resolution chest CT scan was performed during a maximal inspiratory breath hold in all patients.

Patient medical records were reviewed, and the following data were collected: gender; age; previous or current smoking; history of extrathoracic cancer; results of the SPN biopsy; and results of follow-up chest CT (cases in which a nodule had been stable for two years or had disappeared were considered negative). The images acquired in the dedicated chest CT performed as part of the ${ }^{18} \mathrm{~F}$-FDG-PET/CT were then analyzed to determine the diameter of the nodule and whether or not there was spiculation. The PET and CT images were fused and evaluated. The nodule uptake of ${ }^{18}$ F-FDG was classified, by its maximum standardized uptake value (SUVmax), as follows ${ }^{(13)}$ : discrete, when the SUVmax was $\leq 2.5$; moderate, when the SUVmax was 2.6-10; or intense, when the SUVmax was $>10$.

\section{Calculation of the pre-test probability of malignancy according to the Mayo Clinic model}

The Mayo Clinic model determines the SPN probability of malignancy with the following formula ${ }^{(11)}: P M=$ $1 /\left(1+e^{-x}\right)$, where $P M$ is the probability of malignancy and $x=-6.8272+0.0391 \times($ age in years $)+0.7917 \times($ previous or current smoking $)+1.3388 \times$ (history of extrathoracic cancer $)+0.1274 \times(\mathrm{SPN}$ diameter in $\mathrm{mm})+1.0407$ $\times$ (presence of spiculation $)+0.7838 \times($ SPN located in the upper lobe). Previous or current smoking, history of extrathoracic cancer, presence of spiculation, and SPN location in the upper lobe are taken as dichotomous variables, meaning that when they are absent they get a score of zero and when they are present they get a score of one.

\section{Calculation of the pre-test probability of malignancy according to the Herder model}

The Herder model determines the probability of malignancy by making use of the Mayo Clinic model together with the ${ }^{18} \mathrm{~F}$-FDG-PET/CT results, according to 
the following formula ${ }^{(12)}: P M=1 /\left(1+e^{-x}\right)$, where $P M$ is the probability of malignancy and $x=-4.739+3.691$ $\times$ (Mayo Clinic probability $)+2.322 \times($ discrete nodule uptake $)+4.617 \times($ moderate nodule uptake $)+4.771 \times$ (intense nodule uptake). The presence of discrete, moderate, and intense uptake are treated as dichotomous variables, meaning that if it is absent it gets a score of zero and if it is present it gets a score of one.

\section{Ability of ${ }^{18}$ F-FDG-PET/CT to identify high or low probability in cases originally classified as having intermediate probability}

Nodules classified by the Mayo Clinic model as having an intermediate probability of malignancy were included in this analysis. In those cases, the probability of malignancy was reclassified according to the Herder model as low $(<5 \%)$, intermediate $(5-65 \%)$, or high $(>65 \%) .{ }^{18} \mathrm{~F}-$ FDG-PET/CT was considered a determinant of the best course of action in the cases reclassified as having a low or high probability, although not in the cases that were not reclassified.

\section{Statistical analysis}

Continuous variables are expressed as mean and standard deviation, whereas categorical variables are expressed as absolute and relative frequencies. To assess the ability of ${ }^{18}$ F-FDG-PET/CT to inform practice, the cases were divided into inconclusive (intermediate probability of malignancy) or conclusive (low or high probability of malignancy). We used McNemar's test to compare the proportions in each model. An additional test was performed only in the cases classified as intermediate probability by the Mayo Clinic model. We used confidence interval (CI) to describe the results of this analysis and considered a $p<0.05$ as significant. MedCalc Software, version 18.2.1 (MedCalc Software bvba, Ostend, Belgium) was used in the analyses.

\section{RESULTS}

A total of 33 patients was enrolled in this study. The mean age was $68.63 \pm 12.20$ years, and $17(51.5 \%)$ of the patients were male. The mean probability of malignancy was $43.2 \pm 25.6 \%$ with the Mayo Clinic model and $47.1 \%$ $\pm 38.9 \%$ with the Herder model. The other variables considered in this study are detailed in Table 1.

According to the Mayo Clinic model, the probability of malignancy was intermediate in 23 cases $(69.7 \%)$, low in $2(0.6 \%)$, and high in $8(2.4 \%)$. When the Herder model was applied in those 23 nodules, $6(26.1 \%)$ were reclassified as low and $8(34.8 \%)$ were reclassified as high, whereas $9(39.1 \%)$ were not reclassified (Figure 1). The difference between the Mayo Clinic model and Herder model, in terms of the proportion of cases converted from inconclusive to conclusive, was $36.4 \%$ (95\% CI: $16.1-56.6 \%$; $p<$ 0.01 ), in favor of the latter model. Of the cases that were
Table 1-Characteristics of the patients and SPNs in our study sample.

\begin{tabular}{lc}
\hline Variable & Value \\
\hline Gender, $\mathrm{n}(\%)$ & $17(51.5 \%)$ \\
$\quad$ Male & $16(48.5 \%)$ \\
$\quad$ Female & $68.63( \pm 12.20)$ \\
Age (years), mean \pm SD & $26(78.8 \%)$ \\
Current or former smoker, $\mathrm{n}(\%)$ & $3(9.1 \%)$ \\
History of extrathoracic cancer, $\mathrm{n}(\%)$ & $1.52( \pm 0.61)$ \\
SPN diameter (cm), mean \pm SD & $18(54.5 \%)$ \\
SPN spiculation, $\mathrm{n}(\%)$ & $20(60.6 \%)$ \\
SPN in the upper lobe, $\mathrm{n}(\%)$ & \\
SPN ${ }^{18}$ F-FDG uptake (SUVmax), $\mathrm{n}(\%)$ & $10(30.3 \%)$ \\
None & $8(24.2 \%)$ \\
$<2.5$ & $13(39.4 \%)$ \\
$2.5-10.0$ & $2(6.1 \%)$ \\
$>10.0$ &
\end{tabular}

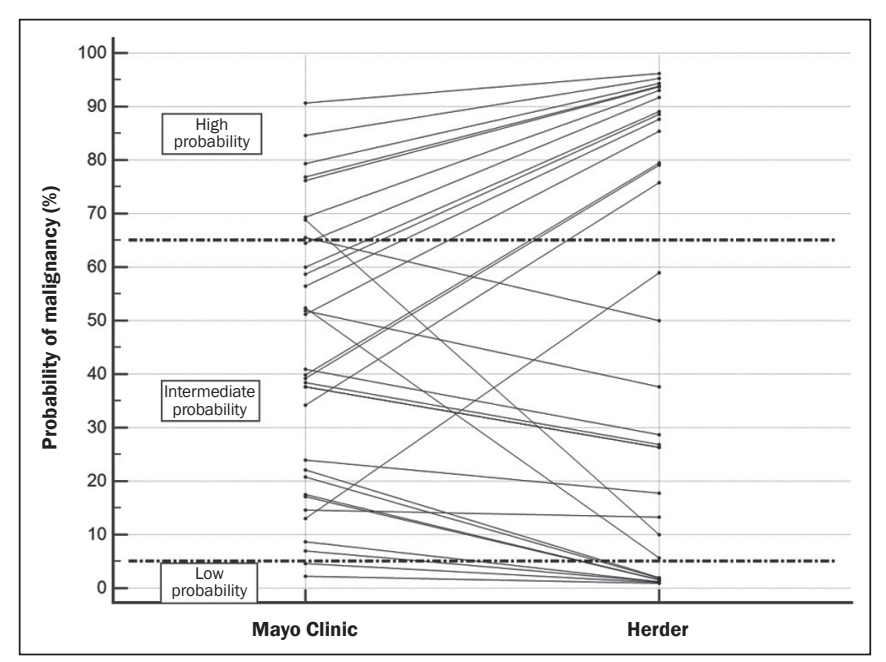

Figure 1. Variation in the probability of malignancy classification per patient according to each model.

classified as having a high or low probability of malignancy by the Mayo Clinic model (Figure 1), none were upgraded and only two were downgraded (from high to intermediate probability) by the Herder model. In addition, when only the cases classified by the Mayo Clinic model as intermediate were considered, that difference increased to $60.9 \%$ (95\% CI: 40.9-80.8\%; $p<0.05$ ), and ${ }^{18}$ F-FDG-PET/CT was the determinant of the course of action in 14 cases $(60.1 \%)$. Figure 2 shows cases that were reclassified on the basis of the ${ }^{18} \mathrm{~F}$-FDG-PET/CT findings.

Of the 33 patients included, nine underwent biopsy for histological confirmation, the probability of malignancy having been classified by the Herder model as high in six and as intermediate in three. All of the high-probability cases were malignant, whereas there were benign and malignant findings among the intermediate-probability cases (Table 2). Another five patients underwent a followup chest CT examination at our center two years later. In each of the five, the nodule was stable, had shrunk, or had disappeared. 

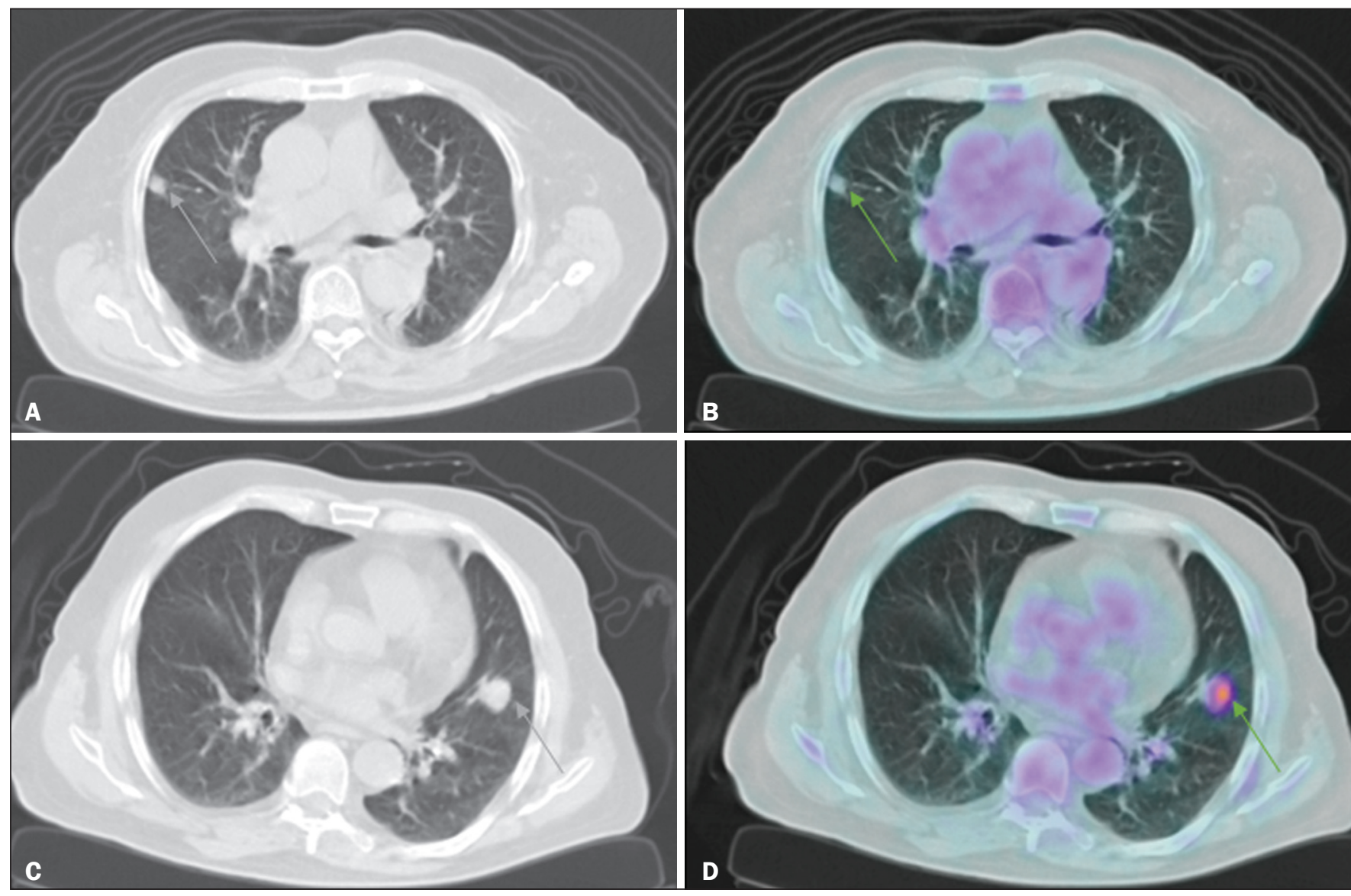

Figure 2. Examples of the use of ${ }^{18} \mathrm{~F}-\mathrm{FDG}-\mathrm{PET} / \mathrm{CT}$ in SPNs. A: A nodule for which the probability of malignancy was $33.2 \%$ on the basis of clinical and CT findings, decreasing to $10 \%$ when the absence of ${ }^{18} \mathrm{~F}$-FDG uptake was taken into account (a follow-up CT scan at two years out showed that the nodule had disappeared). B: A nodule for which the probability of malignancy was $6.2 \%$ on the basis of clinical and CT findings, increasing to $75.8 \%$ when the moderate ${ }^{18} \mathrm{~F}-\mathrm{FDG}$ uptake was taken into account (a subsequent biopsy revealed an adenocarcinoma).

\section{DISCUSSION}

A number of recent studies conducted in Brazil have emphasized the importance of nuclear medicine, especially ${ }^{18}$ F-FDG-PET/CT, for the diagnosis and follow-up of various illnesses ${ }^{(14-18)}$. The present study showed how ${ }^{18}$ F-FDG-PET/CT can aid clinicians during the decisionmaking process in cases of SPN with an intermediate probability of malignancy. It is noteworthy that ${ }^{18} \mathrm{~F}$-FDGPET/CT modified the probability of malignancy of SPNs in more than half of the cases evaluated, downgrades and upgrades occurring at approximately the same frequency. In addition, the analysis of the cases that underwent biopsy showed that all nodules with a high probability of malignancy had a neoplastic origin. These findings underscore the value of using ${ }^{18} \mathrm{~F}$-FDG-PET/CT to define the proper management of cases of SPN.

In cases of SPN, clinical decision-making can be tricky, especially given the high prevalence and varied

Table 2-Detailed description of the 14 SPNs submitted to biopsy or follow-up CT.

\begin{tabular}{|c|c|c|}
\hline $\begin{array}{l}\text { Pre-test probability of malig- } \\
\text { nancy according to the Herder } \\
\text { model }\end{array}$ & $\begin{array}{l}\text { SPNs for which results } \\
\text { were available } \\
\text { (n) }\end{array}$ & Results of a biopsy or follow-up CT \\
\hline High & 6 & $\begin{array}{l}\text { - } 1 \text { small-cell carcinoma } \\
\text { - } 5 \text { adenocarcinomas of pulmonary origin }\end{array}$ \\
\hline Intermediate & 5 & $\begin{array}{l}\text { - } 1 \text { benign granuloma } \\
\text { - } 1 \text { metastasis of a papillary thyroid carcinoma } \\
\text { - } 1 \text { adenocarcinoma of pulmonary origin } \\
\text { - } 1 \text { follow-up CT scan, acquired after } 2 \text { years, showing considerable nodule shrinkage } \\
\text { - } 1 \text { follow-up CT scan showing nodule disappearance }\end{array}$ \\
\hline Low & 3 & $\begin{array}{l}\text { - } 2 \text { follow-up CT scans, acquired after } 2 \text { years, showing lesion stability } \\
\text { - } 1 \text { follow-up CT scan showing disappearance of the nodule }\end{array}$ \\
\hline
\end{tabular}


etiology of the condition ${ }^{(19)}$. In addition, there can be a wide variety of management options, ranging from simple follow-up CT scans to invasive procedures, such as biopsy and surgery ${ }^{(1,5)}$. With that in mind, clinical models were developed to estimate the probability of malignancy in SPNs. One, the Mayo Clinic model, defines the probability of malignancy as low $(<5 \%)$, intermediate (between $5 \%$ and $65 \%)$, or high $(>65 \%)$ on the basis of epidemiological and radiological data ${ }^{(11)}$.

Although the management of cases with a high or low probability of malignancy is well-established, the same is not true for cases with an intermediate probability. Biopsy of the SPN can be an alternative in such cases ${ }^{(1)}$. However, histological confirmation of a pulmonary nodule always requires an invasive procedure, with percutaneous access or even thoracotomy, and is subject to complications such as pneumothorax and hemorrhage, with incidence rates of up to $40 \%$ and $33 \%$, respectively ${ }^{(20)}$. In addition, the accuracy of an SPN biopsy depends on the location and size of the nodule, and on the technique used, varying from below $50 \%$ to almost $100 \%$, depending on the study analyzed ${ }^{(21)}$. Therefore, the use of ${ }^{18} \mathrm{~F}$-FDGPET/CT can help define which patients should undergo biopsy or surgery ${ }^{(1)}$, reducing the number of complications secondary to the procedure.

The use of ${ }^{18}$ F-FDG-PET/CT in SPN can also inform professionals about the best biopsy site when a biopsy is needed $^{(22)}$. Larger nodules may present heterogeneity, with central areas of hypometabolism, and biopsy of the site where there is more intense ${ }^{18} \mathrm{~F}$-FDG uptake is recommended. In addition, the quantification of the probability of malignancy is more accurate with ${ }^{18} \mathrm{~F}$-FDG-PET/CT ${ }^{(12)}$, as has been demonstrated in other populations ${ }^{(13,23)}$.

In the present study, ${ }^{18} \mathrm{~F}$-FDG-PET/CT was able to redefine intermediate probability of malignancy more accurately in $60.9 \%$ of the cases (95\% CI: $40.9-80.8 \%$; $p<$ 0.05 ). Of those, $26.1 \%$ were reclassified as having a low probability, which led to fewer invasive procedures, and $34.8 \%$ were reclassified as having a high probability of malignancy, in which case ${ }^{18}$ F-FDG-PET/CT enabled earlier staging in case there was confirmation of malignancy later. Therefore, it is clear that ${ }^{18} \mathrm{~F}$-FDG-PET/CT can aid clinical decision-making in the context of an SPN, providing patients with the following benefits: prevention of unnecessary invasive procedures, guiding the biopsy, and early, complete staging.

Among the nine SPNs biopsied, the probability of malignancy was classified as high in six and as intermediate in three. Of the three nodules with an intermediate probability, two had a malignant origin, one being an adenocarcinoma and the other being a metastasis of a papillary thyroid carcinoma-a condition that may present low ${ }^{18} \mathrm{~F}$ FDG avidity ${ }^{(24)}$, and the remaining nodule was a benign granuloma. Therefore, when it is not possible to achieve a clear definition of the probability of malignancy for an
SPN, it is necessary to use invasive methods to further investigate the nodule, in order to define the most appropriate course of action, despite the decrease in diagnostic accuracy in such cases ${ }^{(1)}$. All cases with a high probability of malignancy had positive biopsies for some type of neoplasm: five were adenocarcinomas and one was a smallcell carcinoma. Among the five cases submitted to radiological follow-up, the Herder model had classified the probability of malignancy as intermediate in three and as low in two; all five patients were doing well. The fact that the results of the biopsies and follow-up PET/CT scans in nodules with an intermediate probability of malignancy showed similar proportions of benign and malignant nodules underscores the need for a more invasive approach or radiological follow-up in such cases.

To use ${ }^{18}$ F-FDG-PET/CT as an auxiliary tool in clinical decision-making, one should be aware of its limitations in the context of SPN. Due to the limited spatial resolution of ${ }^{18} \mathrm{~F}$-FDG-PET/CT, its use is not recommended for SPNs smaller than $8 \mathrm{~mm}^{(1,6,25)}$. Although the vast majority of pulmonary neoplasms have high ${ }^{18} \mathrm{~F}$-FDG avidity, some tumors do not, including mucinous carcinomas ${ }^{(26)}$ or pulmonary metastases, in which the primary tumor also has a low glycolytic activity ${ }^{(24)}$. In addition, inflammatory and infectious pulmonary conditions can have a presentation similar to that of SPN, with high ${ }^{18} \mathrm{~F}$-FDG avidity, which results in higher false-positive rates ${ }^{(27)}$. In regions with a high prevalence of granulomatous diseases, this can be a particularly problematic, because it can decrease the specificity of the method ${ }^{(27,28)}$.

It is noteworthy that, in the present study none of the SPNs classified as having a high probability of malignancy were found to be caused by infectious or inflammatory processes. Most of the patients who undergo ${ }^{18} \mathrm{~F}-\mathrm{FDG}$ PET/CT scans in Brazil have private health insurance plans ${ }^{(29)}$ because they belong to the higher socioeconomic classes that are therefore at a lower risk of developing tuberculosis $^{(30)}$ and other infectious respiratory diseases ${ }^{(31)}$. That was also observed in another study, conducted at a private hospital in Brazil, in which nearly 93\% of the SPNs with an SUVmax $>2.5$ were malignant ${ }^{(32)}$. Therefore, to optimize the use of ${ }^{18} \mathrm{~F}-\mathrm{FDG}-\mathrm{PET} / \mathrm{CT}$ in SPNs, it is important to consider other patient epidemiological data regarding the presence of infectious lung diseases.

Other limitations of ${ }^{18}$ F-FDG-PET/CT in the investigation of SPN are the limited availability and high cost of the method. In Brazil, access to ${ }^{18}$ F-FDG-PET/CT for the investigation of SPN is limited and is quite heterogeneous among the different regions of the country ${ }^{(29)}$.

\section{CONCLUSION}

This study showed that the use of ${ }^{18}$ F-FDG-PET/CT changed the pre-test probability of malignancy classification of more than half of the SPNs classified as intermediate by a model that used patient clinical and radiological 
data only, confirming that ${ }^{18} \mathrm{~F}$-FDG-PET/CT is an important tool to aid clinical decision-making in such cases.

\section{REFERENCES}

1. Harzheim D, Eberhardt R, Hoffmann H, et al. The solitary pulmonary nodule. Respiration. 2015;90:160-72.

2. Holin SM, Dwork RE, Glaser S, et al. Solitary pulmonary nodules found in a community-wide chest roentgenographic survey; a fiveyear follow-up study. Am Rev Tuberc. 1959;79:427-39.

3. Henschke CI, Naidich DP, Yankelevitz DF, et al. Early lung cancer action project: initial findings on repeat screenings. Cancer. 2001; 92:153-9.

4. Mott TF. Lung cancer: screening and evaluation of patients with solitary pulmonary nodules. FP Essent. 2018;464:17-22.

5. Ito M, Miyata Y, Okada M. Management pathways for solitary pulmonary nodules. J Thorac Dis. 2018;10(Suppl 7):S860-S866.

6. Mosmann MP, Borba MA, Macedo FP, et al. Solitary pulmonary nodule and (18)F-FDG PET/CT. Part 1: epidemiology, morphological evaluation and cancer probability. Radiol Bras. 2016;49:35-42.

7. Suh YJ, Lee JH, Hur J, et al. Predictors of false-negative results from percutaneous transthoracic fine-needle aspiration biopsy: an observational study from a retrospective cohort. Yonsei Med J. 2016;57:1243-51.

8. Gould MK, Sanders GD, Barnett PG, et al. Cost-effectiveness of alternative management strategies for patients with solitary pulmonary nodules. Ann Intern Med. 2003;138:724-35.

9. Macheda ML, Rogers S, Best JD. Molecular and cellular regulation of glucose transporter (GLUT) proteins in cancer. J Cell Physiol. 2005;202:654-62.

10. Hashimoto Y, Tsujikawa T, Kondo C, et al. Accuracy of PET for diagnosis of solid pulmonary lesions with 18F-FDG uptake below the standardized uptake value of 2.5. J Nucl Med. 2006;47:426-31.

11. Swensen SJ, Silverstein MD, Ilstrup DM, et al. The probability of malignancy in solitary pulmonary nodules. Application to small radiologically indeterminate nodules. Arch Intern Med. 1997;157: 849-55.

12. Herder GJ, van Tinteren H, Golding RP, et al. Clinical prediction model to characterize pulmonary nodules: validation and added value of $18 \mathrm{~F}$-fluorodeoxyglucose positron emission tomography. Chest. 2005;128:2490-6.

13. Al-Ameri A, Malhotra P, Thygesen H, et al. Risk of malignancy in pulmonary nodules: a validation study of four prediction models. Lung Cancer. 2015;89:27-30.

14. Romanato J, Menezes MR, Santos AO, et al. ${ }^{18}$ F-FDG PET/CT performed immediately after percutaneous ablation to evaluate outcomes of the procedure: preliminary results. Radiol Bras. 2019; 52:24-32.

15. Birelli B, Oliveira M, Santos AO, et al. SPECT/CT with ${ }^{99 \mathrm{~m}} \mathrm{Tc}$-sestamibi for the evaluation of skeletal muscle perfusion after electrical muscle stimulation in athletes. Radiol Bras. 2019;52:92-6.

16. Vale RHB, Ferraro DA, Duarte PS, et al. Bone marrow uptake of ${ }^{18}$ F-fluorodeoxyglucose in Hodgkin lymphoma without bone involvement: comparison between patients with and without B symptoms. Radiol Bras. 2018;51:76-80.
17. Ono CR, Tedde ML, Scordamaglio PR, et al. Pulmonary inhalationperfusion scintigraphy in the evaluation of bronchoscopic treatment of bronchopleural fistula. Radiol Bras. 2018;51:385-90.

18. Farias LPG, Padilha IG, Lemos MLR, et al. Pulmonary cryptococcosis mimicking neoplasm in terms of uptake PET/CT. Radiol Bras. 2018;51:63-4.

19. Ost D, Fein AM, Feinsilver SH. The solitary pulmonary nodule. N Engl J Med. 2003;348:2535-42.

20. Yeow KM, See LC, Lui KW, et al. Risk factors for pneumothorax and bleeding after CT-guided percutaneous coaxial cutting needle biopsy of lung lesions. J Vasc Interv Radiol. 2001;12:1305-12.

21. Yang W, Sun W, Li Q, et al. Diagnostic accuracy of CT-guided transthoracic needle biopsy for solitary pulmonary nodules. PLoS One. 2015;10:e131373.

22. Gould MK, Donington J, Lynch WR, et al. Evaluation of individuals with pulmonary nodules: when is it lung cancer? Diagnosis and management of lung cancer, 3rd ed: American College of Chest Physicians evidence-based clinical practice guidelines. Chest. 2013; 143(5 Suppl):e93S-e120S.

23. Perandini S, Soardi GA, Larici AR, et al. Multicenter external validation of two malignancy risk prediction models in patients undergoing 18F-FDG-PET for solitary pulmonary nodule evaluation. Eur Radiol. 2017;27:2042-6.

24. Marcus C, Whitworth PW, Surasi DS, et al. PET/CT in the management of thyroid cancers. AJR Am J Roentgenol. 2014;202:1316-29.

25. Hochhegger B, Alves GRT, Irion KL, et al. PET/CT imaging in lung cancer: indications and findings. J Bras Pneumol. 2015;41:264-74.

26. Shim SS, Han J. FDG-PET/CT imaging in assessing mucin-producing non-small cell lung cancer with pathologic correlation. Ann Nucl Med. 2010;24:357-62.

27. Purandare NC, Pramesh CS, Agarwal JP, et al. Solitary pulmonary nodule evaluation in regions endemic for infectious diseases: do regional variations impact the effectiveness of fluorodeoxyglucose positron emission tomography/computed tomography. Indian J Cancer. 2017;54:271-5.

28. Deppen SA, Davis WT, Green EA, et al. Cost-effectiveness of initial diagnostic strategies for pulmonary nodules presenting to thoracic surgeons. Ann Thorac Surg. 2014;98:1214-22.

29. Tsukazan MT, Terra RM, Detterbeck F, et al. Management of lung nodules in Brazil-assessment of realities, beliefs and attitudes: a study by the Brazilian Society of Thoracic Surgery (SBCT), the Brazilian Thoracic Society (SBPT) and the Brazilian College of Radiology (CBR). J Thorac Dis. 2018;10:2849-56.

30. Geraldes Santos ML, Figueiredo Vendramini SH, Gazetta CE, et al. Poverty: socioeconomic characterization at tuberculosis. Rev Lat Am Enfermagem. 2007;15 Spec No:762-7.

31. Thörn LK, Minamisava R, Nouer SS, et al. Pneumonia and poverty: a prospective population-based study among children in Brazil. BMC Infect Dis. 2011;11:180.

32. Martins RC, Almeida SA, Siciliano AA, et al. Value of [18F]-FDG$\mathrm{PET} / \mathrm{CT}$ as a predictor of cancer in solitary pulmonary nodule. $\mathrm{J}$ Bras Pneumol 2008;34:473-80. 